\title{
Tacrolimus for ulcerative colitis in children: a multicenter survey in Japan
}

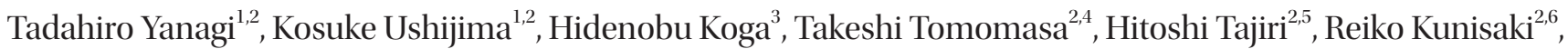 \\ Takashi Isihige ${ }^{2,7}$, Hiroyuki Yamada $^{2,8}$, Katsuhiro Arai $^{2,9}$, Atsushi Yoden ${ }^{2,10}$, Tomoki Aomatsu ${ }^{2,10}$, Satoru Nagata ${ }^{2,11}$, \\ Keiichi Uchida ${ }^{2,12}$, Yoshikazu Ohtsuka ${ }^{2,13}$, Toshiaki Shimizu ${ }^{2,13}$ \\ ${ }^{1}$ Department of Pediatrics and Child Health, Kurume University School of Medicine, Kurume; ${ }^{2}$ Members of the Japanese Society for Pediatric \\ Inflammatory Bowel Disease Working Group; ${ }^{3}$ Clinical Research Support Office, Aso Iizuka Hospital, Iizuka; ${ }^{4}$ PAL Children's Clinic, Isesaki; \\ ${ }^{5}$ Department of Pediatrics, Osaka General Medical Center, Osaka; ${ }^{6}$ Inflammatory Bowel Center, Yokohama City University Medical Center, \\ Yokohama; ${ }^{7}$ Department of Pediatrics, Gunma University Graduate School of Medicine, Maebashi, ${ }^{8}$ Department of Pediatric Gastroenterology, \\ Nutrition and Endocrinology, Osaka Women's and Children's Hospital, Osaka; ${ }^{9}$ Division of Gastroenterology, National Center for Child \\ Health and Development, Tokyo; ${ }^{10}$ Department of Pediatrics, Osaka Medical College, Osaka; ${ }^{11}$ Department of Pediatrics, Tokyo Women's \\ Medical University Hospital, Tokyo; ${ }^{12}$ Department of Gastrointestinal and Pediatric Surgery, Mie University Graduate School of Medicine, Tsu; \\ ${ }^{13}$ Department of Pediatrics and Adolescent Medicine, Juntendo University Graduate School of Medicine, Tokyo, Japan
}

Background/Aims: Tacrolimus is effective for refractory ulcerative colitis in adults, while data for children is sparse. We aimed to evaluate the effectiveness and safety of tacrolimus for induction and maintenance therapy in Japanese children with ulcerative colitis. Methods: We retrospectively reviewed the multicenter survey data of 67 patients with ulcerative colitis aged $<17$ years treated with tacrolimus between 2000 and 2012. Patients' characteristics, disease activity, Pediatric Ulcerative Colitis Activity Index (PUCAI) score, initial oral tacrolimus dose, short-term (2-week) and long-term (1-year) outcomes, steroid-sparing effects, and adverse events were evaluated. Clinical remission was defined as a PUCAI score < 10; treatment response was defined as a PUCAI score reduction of $\geq 20$ points compared with baseline. Results: Patients included 35 boys and 32 girls (median [interquartile range] at admission: 13 [11-15] years). Thirty-nine patients were steroid-dependent and 26 were steroidrefractory; 20 had severe colitis and 43 had moderate colitis. The initial tacrolimus dose was $0.09 \mathrm{mg} / \mathrm{kg} / \mathrm{day}$ (range, $0.05-0.12$ $\mathrm{mg} / \mathrm{kg} /$ day). The short-term clinical remission rate was $47.8 \%$, and the clinical response rate was $37.3 \%$. The mean prednisolone dose was reduced from $19.2 \mathrm{mg} /$ day at tacrolimus initiation to $5.7 \mathrm{mg} /$ day at week $8(P<0.001)$. The adverse event rate was 53.7\%; 6 patients required discontinuation of tacrolimus therapy. Conclusions: Tacrolimus was a safe and effective second-line induction therapy for steroid-dependent and steroid-refractory ulcerative colitis in Japanese children. (Intest Res 2019;17:476485)

Key Words: Immunologic factors; Biological factors; Remission induction; Colectomy

\section{INTRODUCTION}

Pediatric patients with UC generally experience more extensive and severe disease than adult patients. ${ }^{1,2}$ The prevalence of steroid-refractory and steroid-dependent colitis is also high-

Received March 29, 2019. Revised June 13, 2019. Accepted July 15, 2019. Correspondence to Tadahiro Yanagi, Department of Pediatrics and Child Health, Kurume University School of Medicine, 67 Asahi-machi, Kurume 830-0011, Japan. Tel: +81-942-31-7565, Fax: +81-942-38-1792, E-mail: yanagi_tadahiro@med.kurume-u.ac.jp er among children than among patients with adult-onset disease. ${ }^{2}$ Steroid-dependent colitis is defined as relapse of symptoms when the steroid dose is reduced after remission, recurrence of symptoms within 3 months after steroid discontinuation, or inability to discontinue steroids within 14-16 weeks. ${ }^{3}$ Steroids should be avoided as maintenance therapy either by increasing other maintenance therapies or by adding secondline therapy. ${ }^{3,4}$ Steroid-refractory colitis is defined as a lack of response to adequate steroid treatment within 3-10 days. Introducing second-line therapies, such as cyclosporine, tacroli- 
mus, or biologics, is necessary to avoid or delay surgery in steroid-refractory patients. ${ }^{3-6}$

In 2009, tacrolimus was approved as a treatment for refractory UC, in Japan. Tacrolimus is an immunomodulator with a macrolide skeleton that was discovered as a metabolite of Streptomyces tsukubaensis and has a mode of action similar to that of cyclosporine. ${ }^{7}$ Tacrolimus combines FKBP-12 inside the cell to form a complex. This complex inhibits calcineurin, a dephosphorylating enzyme inside the helper-T cell. Calcineurin inhibition suppresses transcription of the early activation genes for cytokines such as interleukin 2, TNF- $\alpha$, and interferon-c in T cells. In summary, tacrolimus is a potent inhibitor of helper-T lymphocyte activation. The immunosuppressive effect of tacrolimus is $30-100$ times greater in vitro and 10-20 times greater in vivo than that of cyclosporine..$^{7-9}$ Because tacrolimus is unaffected by bile acids and mucosal injury, intestinal absorption is more consistent than for cyclosporine, even in the presence of gastrointestinal disease. ${ }^{8}$

A placebo-controlled double-blind study of oral tacrolimus therapy assessed efficacy in adult patients with refractory UC. ${ }^{10}$ In a systematic review of 2 randomized controlled trials, tacrolimus at high trough concentrations showed significantly greater efficacy than placebo at 2 weeks and demonstrated significant dose-dependent efficacy in patients with UC. ${ }^{11}$

The European Crohn's and Colitis Organisation and the European Society for Paediatric Gastroenterology Hepatology and Nutrition guidelines for pediatric patients with UC state, "Cyclosporine or tacrolimus started during an episode of acute severe colitis should be discontinued after 4 months, bridging to thiopurines.",3,4 In these guidelines, tacrolimus is positioned as a second-line treatment for steroid-refractory severe UC. In the Japanese treatment guidelines for $\mathrm{UC}^{12}$ tacrolimus is listed as a treatment for fulminant or refractory UC. The Japanese guidelines state that the administration dose should aim to reach an initial serum trough level of $10-15 \mathrm{ng} / \mathrm{mL}$ and should then be adjusted to obtain an ongoing trough level of 5-10 ng/ $\mathrm{mL}$. After induction, treatment gradually changes to maintenance therapy with azathioprine (AZA) or 6-mercaptopurine (6-MP). The aim of this study was to evaluate the effectiveness and safety of tacrolimus for UC in children, in Japan.

\section{METHODS}

\section{Patients}

This study was a retrospective survey involving multiple centers in Japan. Data were collected from a multicenter survey of infliximab, adalimumab, cyclosporine, and tacrolimus use in pediatric patients diagnosed with IBD between 2000 and 2012. The survey was sent to 683 facilities in Japan from December 2012 to March 2013, including 513 pediatric facilities, 91 pediatric surgery facilities, and 79 internal medicine facilities specializing in IBD. Eligible patients for this study were Japanese children under 17 years of age with UC who were treated with tacrolimus. The diagnosis of UC was established with the Porto criteria ${ }^{13}$ or standard criteria ${ }^{14}$ and was based on clinical assessment, radiology, endoscopy, and histology at each facility. Steroid-refractory colitis is defined as a lack of response to adequate steroid treatment within 3-10 days. Steroid-dependent colitis is defined as relapse of symptoms when the steroid dose is reduced after remission, recurrence of symptoms within 3 months after steroid discontinuation, or inability to discontinue steroids within 14-16 weeks. ${ }^{3}$ After identifying patients' data for inclusion based on the medical records, each facility representative completed the secondary questionnaire (Supplementary Material 1).

\section{Evaluation}

The primary focus of the evaluation was short- and long-term clinical outcomes. We defined a short-term effect as a response within 2 weeks of administration of tacrolimus and long-term effects as the event-free survival rate 1 year after tacrolimus administration, which was defined as rescue therapy-free and surgery-free survival at 1 year. We used the Pediatric Ulcerative Colitis Activity Index (PUCAI) score, ${ }^{15}$ which is the standard global scoring system, and which ranges from 0 to 85 , to evaluate tacrolimus efficacy. Clinical remission was defined as a PUCAI score < 10; scores of 10-34 indicated mild activity, $35-64$ indicated moderate activity, and $\geq 65$ indicated severe activity. Response to tacrolimus was defined as a PUCAI score decrease of $\geq 20$ points compared with baseline. If the PUCAI score did not change or increased, tacrolimus therapy was regarded as ineffective. Relapse was defined as an exacerbation of symptoms or an increase in PUCAI score after tacrolimus administration. The PUCAI score was determined from medical record data collected in the secondary survey. We also evaluated the following parameters at the time of tacrolimus administration: patients' characteristics, PUCAI score, initial tacrolimus dose, highest blood trough concentration within 2 weeks of beginning tacrolimus therapy, period from diagnosis to first tacrolimus administration, tacrolimus treatment period, time to relapse after tacrolimus administration, steroid-sparing effects, and use of tacrolimus as bridge therapy to mainte- 
nance strategies among patients with remission or response. Furthermore, we analyzed any parameters associated with short- and long-term outcomes.

Second, we compared patients' demographics, short-term tacrolimus treatment effect, time to relapse or surgery, and long-term tacrolimus treatment effect among steroid-refractory patients versus steroid-dependent patients.

Adverse events were assessed in all patients during tacrolimus administration. Complications leading to hospitalization, death, or discontinuation of treatment were considered seri- ous adverse events.

\section{Statistical Analyses}

All variables are expressed as mean, medians (interquartile ranges, IQR) or number (\%). We compared proportions between any 2 categorical variables with Fisher exact test and compared continuous variables with the Wilcoxon rank sum test (the Mann-Whitney $U$-test). One-way ANOVA or KruskalWallis rank test were used to compare more than 3 or more groups of continuous variables and Fisher exact test were used

Table 1. Patient's Demographics $(n=67)$

\begin{tabular}{|c|c|c|c|c|c|c|}
\hline \multirow[b]{2}{*}{ Variable } & \multirow{2}{*}{$\begin{array}{c}\text { At } \\
\text { diagnosis }\end{array}$} & \multirow{2}{*}{$\begin{array}{c}\text { Before } \\
\text { adminis- } \\
\text { tration }\end{array}$} & \multicolumn{4}{|c|}{ At administration } \\
\hline & & & $\begin{array}{l}\text { All patients } \\
(n=67)\end{array}$ & $\begin{array}{l}\text { Steroid-dependent } \\
\quad(n=39)\end{array}$ & $\begin{array}{l}\text { Steroid-refractory } \\
\quad(n=26)\end{array}$ & $P$-value ${ }^{a}$ \\
\hline Sex & & & & & & 1.000 \\
\hline Male & 35 (52.2) & & & $20(51.3)$ & $14(53.8)$ & \\
\hline Female & $32(47.8)$ & & & $19(48.7)$ & $12(46.2)$ & \\
\hline Age (yr) & $11.7(9.2-13.7)$ & & $13.0(11.0-15.0)$ & $13.0(11.5-14.3)$ & $13.0(9.4-15.4)$ & 0.940 \\
\hline Family history & $4(6.0)$ & & & & & \\
\hline \multicolumn{7}{|l|}{ Medical history } \\
\hline 5-ASA & & $66(98.5)$ & 56 (83.6) & 36 (92.3) & $18(69.2)$ & 0.021 \\
\hline Steroid & & 66 (98.5) & $49(73.1)$ & $23(59.0)$ & $26(100.0)$ & $<0.001$ \\
\hline AZA/6-MP & & $34(50.7)$ & $26(38.8)$ & $20(51.3)$ & $6(23.1)$ & 0.038 \\
\hline Leukocyte apheresis & & $32(47.8)$ & $13(19.4)$ & $6(15.4)$ & $6(23.1)$ & 0.520 \\
\hline Cyclosporine & & $7(10.4)$ & $1(1.5)$ & 0 & $1(3.8)$ & 0.400 \\
\hline Anti-TNF agents & & $3(4.5)$ & 0 & 0 & 0 & \\
\hline Extent of disease $^{b}$ & & & & & & 0.074 \\
\hline Proctitis & $3(4.6)$ & & 0 & 0 & 0 & \\
\hline Left-sided & $5(7.7)$ & & $11(16.9)$ & $9(23.1)$ & $1(3.8)$ & \\
\hline Pancolitis & $57(87.7)$ & & $54(83.1)$ & $30(76.9)$ & $23(88.5)$ & \\
\hline Severity & & & & & & 0.020 \\
\hline Mild & $3(5.0)$ & & $4(6.0)$ & $4(10.3)$ & 0 & \\
\hline Moderate & $34(56.7)$ & & $43(64.2)$ & $28(71.8)$ & $14(53.8)$ & \\
\hline Severe & $23(38.3)$ & & $20(29.8)$ & $7(17.9)$ & $12(46.2)$ & \\
\hline PUCAI & $65(45.0-70.0)$ & & 55 (35.0-65.0) & $40(25.0-65.0)$ & $60(50.0-65.0)$ & 0.038 \\
\hline $\begin{array}{l}\text { Period from diagnosis to first } \\
\text { administration of tacrolimus (mon) }\end{array}$ & & & $10(2-17)$ & $15(8-33)$ & $2(1-9)$ & $<0.001$ \\
\hline \multicolumn{7}{|l|}{ Tacrolimus } \\
\hline Initial dose (mg/kg/day) & & & $0.09(0.05-0.12)$ & $0.08(0.05-0.10)$ & $0.09(0.05-0.12)$ & 0.460 \\
\hline Highest blood trough concentration & (ng/mL) & & $12.4(9.2-15.2)$ & $11.9(7.6-14.3)$ & $12.8(10.3-16.2)$ & 0.290 \\
\hline
\end{tabular}

Values are presented as number (\%) or median (interquartile range).

${ }^{a}$ Fisher exact test for comparisons between steroid-dependent and steroid-refractory groups.

'Includes 65 patients; 2 patients had no data. There were 24 steroid-refractory patients, and 2 patients had no data.

Includes 60 cases at diagnosis; 7 patients had no data.

5-ASA, 5-aminosalicylic acid; AZA, azathioprine; 6-MP, 6-mercaptopurine; PUCAI, Pediatric Ulcerative Colitis Activity Index. 
for categorical variables. Kaplan-Meier estimation was used for event-free time analysis, and the log-rank test was used for these comparisons. All reported $P$-values are two-sided; $P<0.05$ was considered statistically significant.

\section{Ethical Considerations}

The Institutional Ethics Committees at Juntendo University and at each institution approved this study. The study protocol was publicly available on each participating institution's homepage, and patients were free to withdraw their data from the study at any time.

\section{RESULTS}

\section{Patients}

We identified 88 pediatric patients with UC treated with tacrolimus, after the first survey. The secondary questionnaire survey was administered to collect data for these 88 patients, and we obtained data for 75 out of 88 patients ( $85.2 \%$ response rate). We retrospectively reviewed the medical records of the 75 patients and excluded 8 patients for whom the initial tacrolimus dose, colitis severity at tacrolimus administration, shortterm effect, and long-term effect were not described. We included data for the remaining 67 patients, in this study. Patients' demographics at the time of the diagnosis of UC are shown in Table 1. This study included 35 boys and 32 girls with a median age at diagnosis of 11.7 years (range, $9.2-13.7$ years). Four patients (6.0\%) had a family history of IBD; 23 patients had severe colitis and 34 had moderate colitis, and the median PUCAI score was 65 (range, 45-70). Regarding disease extent, almost all patients $(87.7 \%)$ had pancolitis. Patients' medical history before tacrolimus administration indicated that 5-aminosalicylic acid (5-ASA) or salazosulfapyridine (66 patients, 98.5\%) and steroids (66 patients, 98.5\%) were used in almost all patients. AZA/6-MP (34 patients, 50.7\%) and leukocyte apheresis (32 patients, $47.8 \%$ ) were used in approximately half of the patients; cyclosporine was used in 7 patients (10.4\%); and antiTNF agents were used in 3 patients (4.5\%).

Patients' demographics at the time of tacrolimus administration are shown in Table 1. The median age at administration was 13 years (range, 11-15 years); 39 patients were steroid-dependent and 26 were steroid-refractory. The remaining 2 patients did not receive steroids. One patient received tacrolimus as diarrhea worsened during administration of 5-ASA. In another patient, tacrolimus was administered because of worsening anemia during treatment with 5-ASA and leukocyte apheresis. Fifty-four patients (83.1\%) had pancolitis, and 11 (16.9\%) had left-sided colitis. Twenty patients (29.8\%) had severe colitis, 43 (64.2\%) had moderate colitis, and 4 (6.0\%) had mild colitis. The median PUCAI score at administration was 55 (range, 35-65). The initial tacrolimus dose was 0.09 $\mathrm{mg} / \mathrm{kg} /$ day (range, $0.05-0.12 \mathrm{mg} / \mathrm{kg} /$ day), and the highest blood trough concentration within 2 weeks was $12.4 \mathrm{ng} / \mathrm{mL}$ (range, $9.2-15.2 \mathrm{ng} / \mathrm{mL}$ ). The median period from diagnosis to

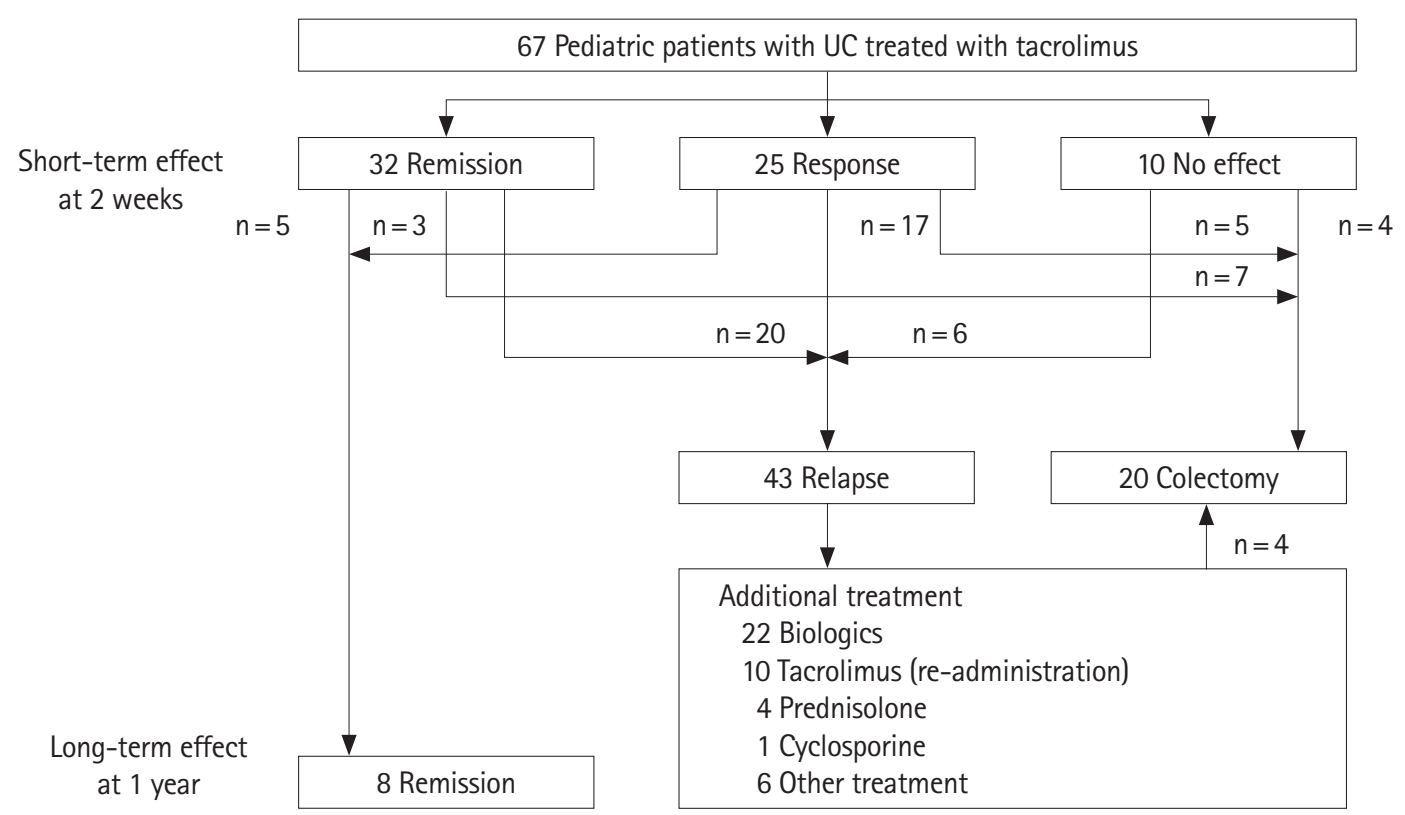

Fig. 1. Patient flow of short- and long-term effects in this study. 
first administration of tacrolimus was 10.0 months (range, 2-17 months); median tacrolimus treatment duration was 18.1 weeks (range, 10.0-41.4 weeks); and the median time to relapse after tacrolimus administration was 14 weeks (range, 8-26 weeks). The mean dose of prednisolone was reduced from $19.2 \mathrm{mg} /$ day at tacrolimus administration onset to 5.7 $\mathrm{mg} /$ day at week 8 . We found a significant steroid-sparing effect of tacrolimus administration $(P<0.001)$.

\section{Primary Outcomes}

Regarding short-term effects, the clinical remission rate was $47.8 \%$ (32 patients), and the clinical response rate was $37.3 \%$ (25 patients). Only 10 patients (14.9\%) showed no treatment effect (Figs. 1, 2). Among 57 patients (85.1\%) with remission or response, 29 patients (43.2\%) had received AZA before tacrolimus administration. Fifteen (22.3\%) were newly-bridged to AZA after tacrolimus and 14 (93.3\% of 15 patients) had relapse or surgery within 1 year.

Regarding long-term effects, only 8 patients ( $11.9 \%$ of all patients and $14 \%$ of patients with short-term remission or response) achieved long-term remission without relapse or surgery (Figs. 1, 2). Five of the 8 patients maintained remission were treated with AZA prior to tacrolimus administration. Two patients were maintained in remission with only 5-ASA. One was administered AZA after tacrolimus administration. However, $86.0 \%$ of 57 patients with short-term remission or response relapsed or need surgery within 1 year. Twenty patients (29.9\%) required surgery. Medical treatment, including biologics (22 patients, 33\%), re-administration of tacrolimus (10 patients, $14.9 \%$ ), and prednisolone (4 patients, $6 \%$ ), was added for patients who did not require surgery. The association between

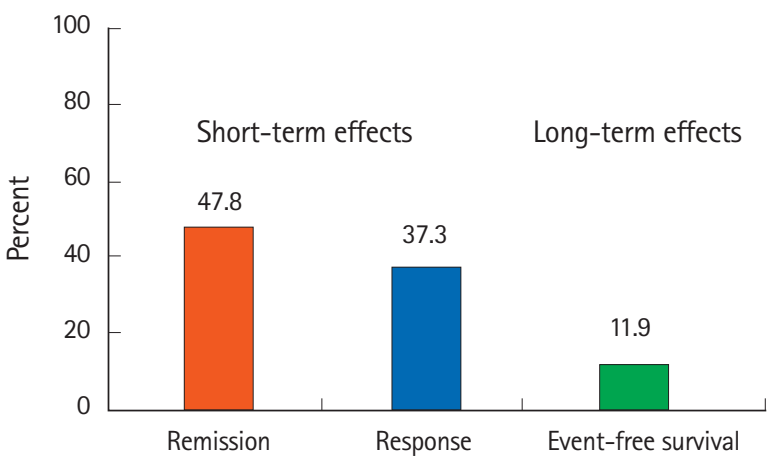

Fig. 2. Short- and long-term effects of tacrolimus therapy. Shortterm effects, defined as remission or response within 2 weeks of tacrolimus therapy, were achieved in $85.1 \%$ of patients (remission: $47.8 \%$; response: $37.3 \%$ ). As a long-term effect, the eventfree survival rate was $11.9 \%$ (14\% of those who achieved shortterm remission or response).

Table 2. Association between Each Parameters and Short-term Outcomes

\begin{tabular}{|c|c|c|c|c|}
\hline \multirow{2}{*}{ Variable } & \multicolumn{3}{|c|}{ Short-term effect } & \multirow{2}{*}{$P$-value ${ }^{a}$} \\
\hline & Remission $(n=32)$ & Response $(n=25)$ & No effect $(n=10)$ & \\
\hline Male sex & $15(22.3)$ & $12(17.9)$ & $8(11.9)$ & 0.169 \\
\hline Age (yr) at tacrolimus administration & $12.9(11.7-15.2)$ & $11.1(8.0-14.5)$ & $13.1(11.8-15.3)$ & 0.460 \\
\hline Period from diagnosis to first tacrolimus administration (mon) & $14.8(2.0-28.5)$ & $14.2(2.0-17.0)$ & $11.3(3.0-12.0)$ & 0.910 \\
\hline Severity & & & & 0.830 \\
\hline Severe & $9(13.4)$ & $9(13.4)$ & $2(3.0)$ & \\
\hline Moderate & $21(31.3)$ & $15(22.3)$ & $7(10.4)$ & \\
\hline Mild & $2(3.0)$ & $1(1.5)$ & $1(1.5)$ & \\
\hline PUCAI $^{b}$ & $45.5(25.0-65.0)$ & $57.4(50.0-65.0)$ & $48.3(40.0-60.0)$ & 0.178 \\
\hline Reason for tacrolimus administration & & & & 0.630 \\
\hline Steroid-dependent & $19(28.3)$ & $14(20.9)$ & $6(9.0)$ & \\
\hline Steroid-refractory & $12(17.9)$ & $11(16.4)$ & $3(4.5)$ & \\
\hline Others & $1(1.5)$ & 0 & $1(1.5)$ & \\
\hline Initial dose (mg/kg/day) & $0.09(0.05-0.12)$ & $0.09(0.06-0.12)$ & $0.08(0.05-0.10)$ & 0.870 \\
\hline Highest blood trough concentration ( $\mathrm{ng} / \mathrm{mL}$ ) & $12.2(9.3-13.8)$ & $11.6(9.2-15.7)$ & $12.4(10.0-15.6)$ & 0.680 \\
\hline
\end{tabular}

Values are presented as number (\%) or median (interquartile range).

${ }^{a}$ Fisher exact test or Kruskal-Wallis test.

${ }^{b}$ Includes 60 cases at diagnosis; 7 patients had no data.

PUCAI, Pediatric Ulcerative Colitis Activity Index. 
each parameter and short- and long-term outcomes is shown in Tables 2 and 3. In the univariate analysis, only initial dose of tacrolimus was the significant association for long-term outcomes, but the other parameters revealed no significant difference in the short- and long-term outcomes. The short-term effects between the remission group and the response group showed no significant difference in the long-term effects in Kaplan-Meier curve analysis (log-rank test, $P=0.33$ ) (Fig. 3). We did not perform the multivariate logistic regression analysis because we did not obtain enough sample size in this study.

\section{Secondary Outcomes}

Thirty-nine patients (58.2\%) were steroid-dependent and 26 (38.8\%) were steroid-refractory. Table 1 shows patients' demographics at the time of tacrolimus administration according to their classification as steroid-dependent or steroid-refractory. Among steroid-dependent patients, the median age was 13 years (range, 11.5-14.3 years) and 19 (48.7\%) were female. Among steroid-refractory patients, the median age was 13 years (range, 9.4-15.4 years) and 12 (46.2\%) were female. At the time of tacrolimus administration, a significantly greater percentage of steroid-dependent patients had received 5-ASA or AZA compared with steroid-refractory patients. Pancolitis was present in $76.9 \%$ of steroid-dependent patients and in 88.5\% of steroid-refractory patients; none of these patients had proctitis. A significantly higher percentage of patients in the steroid-refractory group (46\%) had severe UC compared with

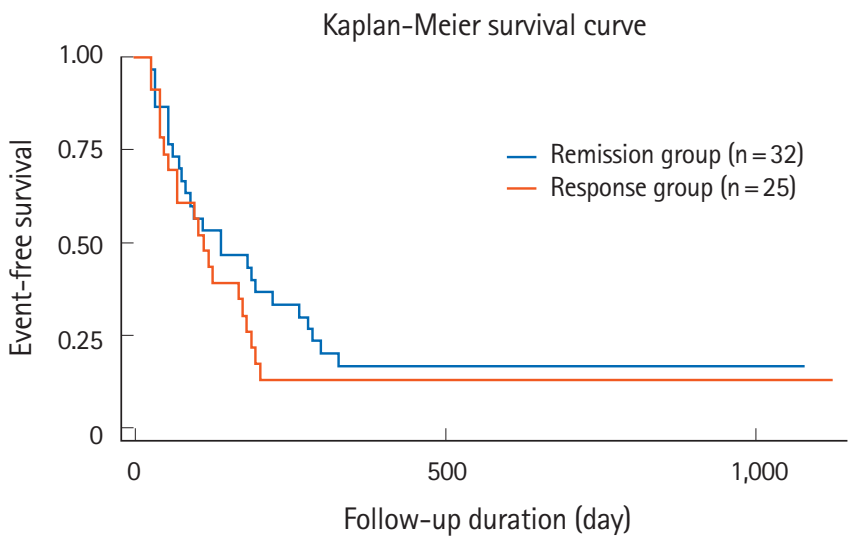

Fig. 3. Event-free survival rate between remission and response groups classified according to short-term effect. We found no significant difference between the 2 groups (remission and response) for the event-free survival rate 1 year after tacrolimus administration, based on Kaplan-Meier analysis (log-rank test, $P=0.33)$

Table 3. Association between Each Parameters and Long-term Outcomes

\begin{tabular}{|c|c|c|c|}
\hline \multirow{2}{*}{ Variable } & \multicolumn{2}{|c|}{ Long-term effect } & \multirow{2}{*}{$P$-value } \\
\hline & Remission $(n=8)$ & Relapse or surgery $(n=49)^{b}$ & \\
\hline Male sex & $5(8.8)$ & $22(38.6)$ & 0.450 \\
\hline Age (yr) at tacrolimus administration & $12.2(11.5-14.8)$ & $12.1(10.0-14.8)$ & 0.890 \\
\hline Period from diagnosis to first tacrolimus administration (mon) & $12.4(2.0-23.5)$ & $14.9(2.0-17.0)$ & 0.850 \\
\hline Severity & & & 0.240 \\
\hline Severe & $1(1.8)$ & $17(29.8)$ & \\
\hline Moderate & $6(10.5)$ & $30(52.6)$ & \\
\hline Mild & $1(1.8)$ & $2(3.5)$ & \\
\hline PUCAI $^{\mathrm{c}}$ & $37.1(20.0-60.0)$ & $53.1(40.0-65.0)$ & 0.085 \\
\hline Reason for tacrolimus administration & & & 0.520 \\
\hline Steroid-dependent & $6(10.5)$ & $27(47.3)$ & \\
\hline Steroid-refractory & $2(3.5)$ & $21(36.8)$ & \\
\hline Others & 0 & $1(1.8)$ & \\
\hline Initial dose (mg/kg/day) & $0.07(0.45-0.65)$ & $0.10(0.06-0.12)$ & 0.027 \\
\hline Highest blood trough concentration ( $\mathrm{ng} / \mathrm{mL}$ ) & $14.1(10.3-17.5)$ & $11.6(8.9-14.3)$ & 0.570 \\
\hline
\end{tabular}

Values are presented as number (\%) or median (interquartile range).

${ }^{a}$ Fisher exact test or Kruskal-Wallis test.

${ }^{b}$ Includes 59 patients; 10 cases had unclear timing data of relapse or surgery.

'Includes 51 cases at diagnosis; 6 patients had no data.

PUCAI, Pediatric Ulcerative Colitis Activity Index. 


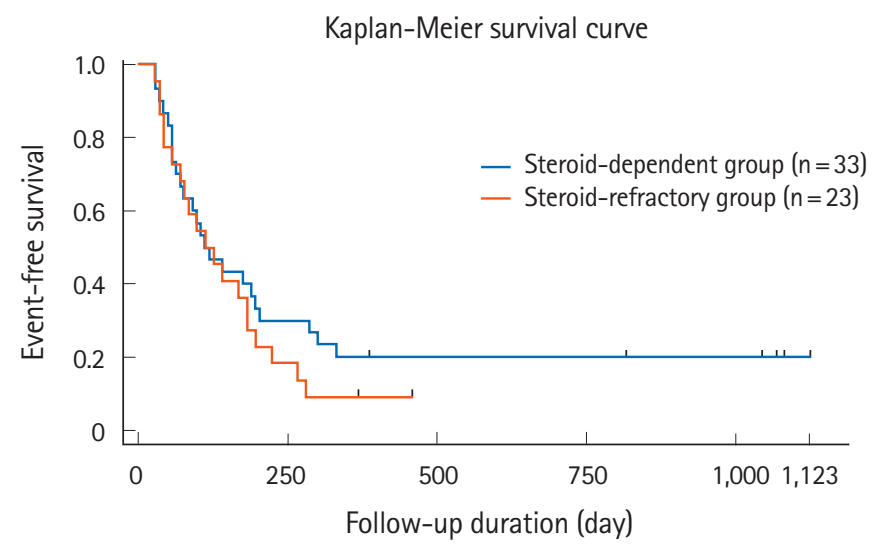

Fig. 4. Event-free survival rate in the steroid-dependent and steroid-refractory groups. We found no significant difference between steroid-dependent and steroid-refractory groups for the event-free survival rate 1 year after tacrolimus administration, based on Kaplan-Meier analysis (log-rank test, $P=0.52$ ).

the steroid-dependent group. The PUCAI score was also higher in the steroid-refractory group than in the steroid-dependent group (60 [50-65] vs. 40 [25-65], respectively; $P=0.038$ ). The period from diagnosis to first administration of tacrolimus was significantly shorter in the steroid-refractory group (2 months; IQR, 1-9 months) than in the steroid-dependent group (15 months; IQR, 8-33 months).

Nineteen patients $(28.3 \%)$ in the steroid-dependent group and $12(17.9 \%)$ in the steroid- refractory group achieved shortterm remission. Fourteen patients $(20.9 \%)$ in the steroid-dependent group and 11 (16.4\%) in the steroid-refractory group achieved short-term treatment response. The difference in the rate of short-term remission and response between groups was not significant $(P=0.686)$.

Twenty-five steroid-dependent patients (37.3\%) and 21 steroid-refractory patients $(31.3 \%)$ had short-term remission or response but relapsed or needed surgery within 1 year. Among patients with remission or response, patients in the steroiddependent group relapsed 280 days (range, 56-301 days) after tacrolimus administration; patients in the steroid-refractory group relapsed 148 days (range, 56-196 days) after tacrolimus administration. The time interval to relapse or colectomy was not significantly different between groups, according to Kaplan-Meier curve analysis (log-rank test, $P=0.52$ ) (Fig. 4).

\section{Safety}

Adverse events were identified in 36 out of 67 patients (53.7\%). Asymptomatic hypomagnesemia occurred in 9 patients (13.4\%) and tremor in 7 patients (10.4\%) (Table 4$)$. Six patients (9.0\%)
Table 4. Adverse Events $(n=67)$

\begin{tabular}{lcc}
\hline Adverse event & No. (\%) & $\begin{array}{c}\text { Discontinuation of } \\
\text { tacrolimus, no. (\%) }\end{array}$ \\
\hline Hypomagnesemia & $9(13.4)$ & - \\
Tremor & $7(10.4)$ & - \\
Infection & $4(6.0)$ & $1(1.5)$ \\
Renal impairment & $4(6.0)$ & $2(3.0)$ \\
Myelosuppression & $4(6.0)$ & $2(3.0)$ \\
Hyperglycemia & $3(4.5)$ & - \\
Headache & $2(3.0)$ & - \\
Hyperkalemia & $2(3.0)$ & - \\
Vomiting & $1(1.5)$ & $1(3.0)$ \\
Pancreatitis & $1(1.5)$ & - \\
Hyperuricemia & $1(1.5)$ & - \\
Total no. of patients & $36(53.7)$ & $6(9.0)$ \\
experiencing adverse events & & \\
\hline
\end{tabular}

Two patients had more than 1 adverse event.

required discontinuation of tacrolimus therapy because of adverse events: 2 (3.0\%) had renal impairment, 2 (3.0\%) had myelosuppression, 1 (1.5\%) developed intestinal infection, and 1 (1.5\%) experienced vomiting. The highest trough concentrations for cases with discontinuation were 6.2 to $13.6 \mathrm{ng} / \mathrm{mL}$, all less than $15 \mathrm{ng} / \mathrm{mL}$. All symptoms improved after tacrolimus discontinuation or with appropriate treatment.

\section{DISCUSSION}

We retrospectively investigated the effectiveness and safety of tacrolimus as second-line treatment for pediatric UC using a multicenter survey. In our study, the rate of remission or response at 2 weeks was $85.1 \%$, and the clinical remission rate was $47.8 \%$ within 2 weeks. Pediatric UC is characterized by more extensive and rapid progression than adult-onset UC, and pediatric patients are more likely to have acute severe exacerbations and lack of response to steroid therapy. ${ }^{1-4,16}$ The steroid failure rate was reported as $34 \%$; therefore, especially in severe cases, second-line therapy should be introduced at an appropriate time to avoid or delay colectomy. ${ }^{4-6}$ Turner et al. ${ }^{17,18}$ proposed determining the timing of second-line therapy based on PUCAI scores.

Second-line therapies for induction of remission in steroidrefractory and steroid-dependent pediatric patients with UC include cyclosporine, anti-TNF- $\alpha$ agents, and tacrolimus. ${ }^{3-6,16,17}$ The reported short-term response rate to cyclosporine among 
pediatric patients is $81 \%$ (range, $76 \%-86 \%),{ }^{6}$ and the reported response rate to infliximab is $75 \%$ (range, $67 \%-83 \%$ ). ${ }^{6} \mathrm{~A}$ double-blind study of adult patients showed a tacrolimus efficacy of $68.4 \% ;{ }^{10}$ however, reports of tacrolimus use for pediatric patients with UC are limited. The effects of tacrolimus for pediatric UC were first reported in $1996,{ }^{19}$ and in 2000 , a multicenter study reported the effects of tacrolimus in 10 pediatric patients with UC. ${ }^{20}$ Five retrospective studies of tacrolimus administration in children with $U^{5,19-22}$ reported a pooled short-term response rate of $79 \%$ (range, $68 \%-87 \%$ ) among patients with steroid-refractory UC. ${ }^{5}$ Similar to previous reports, we found that tacrolimus was an effective second-line induction therapy in steroid-refractory and steroid-dependent pediatric patients with UC. In our study, the rate of remission or response 2 weeks after beginning tacrolimus was $85.1 \%$, and the clinical remission rate was $47.8 \%$ within 2 weeks. Ogata et al..$^{10}$ demonstrated that their high-trough group $(10-15 \mathrm{ng} / \mathrm{mL})$ had a higher remission rate than the low-trough and placebo groups. However, in our study, we found no significant difference in shortterm effects based on the initial tacrolimus dose or trough level, although many patients had no documented trough level in the target zone. The fact that the initial dosage and dose regulation varied widely by facility is suspected to have strongly influenced our results when evaluating the short-term effects of tacrolimus therapy. Although previous studies cited the steroid-sparing effect of tacrolimus administration, no clear numerical value was reported in previous pediatric studies. Similar to a study of adults with $\mathrm{UC},{ }^{10}$ tacrolimus use in this study resulted in a significant steroid-sparing effect, with a reduction in prednisolone dose from $19.2 \mathrm{mg} /$ day initially to $5.7 \mathrm{mg} /$ day.

The reported pooled rate of colectomy-free status $1-2$ years after tacrolimus administration in pediatric steroid-refractory UC is $43 \%$ (range, $32 \%-54 \%$ ). ${ }^{5}$ A meta-analysis of observational studies in adults reported a higher colectomy-free rate of $69 \%$ among patients with moderate-to-severe UC. ${ }^{11}$ However, only $14 \%$ of our patients with an initial response to tacrolimus maintained remission without relapse. Even though 1 patient was changed to AZA therapy, only 8 patients remained in remission 1 year after tacrolimus administration. After an initial response to tacrolimus, $82.5 \%$ of our patients experienced relapse, and many of these patients underwent third-line therapy with biologics, readministration of tacrolimus, or steroids, and were able to avoid surgery. The European Crohn's and Colitis Organisation guidelines address bridging to AZA/6-MP for maintenance therapy. ${ }^{3,46}$ Watson et al. ${ }^{22}$ reported that maintenance to a remission of $50 \%$ has been obtained in the long- term by bridging to AZA/6-MP (30\%) or infliximab (20\%) after administration of tacrolimus to steroid-refractory pediatric patients. However, in our study, the large number of steroiddependent patients and the fact that $50 \%$ of the cases had been administered AZA before the introduction of tacrolimus may have led to a reduction in long-term effects. On the other hand, 15 patients with remission or response in the short-term effect were newly-bridged to azathioprine after tacrolimus, but only 1 patient could achieve remission after 1 year without rescue therapy. Thiopurine preparations alone may be insufficient to maintain long-term remission; however, it is possible that tacrolimus will be a useful bridge therapy for vedolizum$\mathrm{ab}$ in future. ${ }^{4,23}$

In univariate analysis, although the initial dose of tacrolimus was associated with the long-term effect, the long-term effect due to the difference of short-term outcomes was not significantly different, and no factor related to the short- and longterm outcomes could be found. Ziring et al. ${ }^{21}$ reported longterm outcomes in steroid-dependent and steroid-refractory patients with pediatric UC. All 9 patients with steroid-refractory UC in that study underwent colectomy within 1 year, whereas 7 out of 9 patients with steroid-dependent UC maintained remission at 1 year. In our study, the event-free survival rate was not significantly different between steroid-dependent and steroid-refractory groups. In steroid-refractory as well as steroid-dependent patients, we should carefully observe the clinical course after response to tacrolimus, considering the possibility of surgery.

Adverse events occurred in $53.7 \%$ of all patients in our study. Ogata et al. ${ }^{10}$ reported that $81.3 \%$ of patients who received tacrolimus had adverse events; however, many of these were mild symptoms, and the authors found no significant difference in the incidence of severe adverse events between the tacrolimus group and placebo group. In contrast, Komaki et al. ${ }^{11}$ suggested that adverse events were more common with tacrolimus than with other treatments, which is 1 reason that administration of tacrolimus is limited to facilities with relatively more patient experience. In studies of pediatric patients, ${ }^{5,19-22}$ hypertension, tremor, hyperglycemia, headache, infection, nephrotoxicity, and seizure have been reported with tacrolimus use, but there have been no reports of serious adverse events. Renal impairment has been reported often, and the incidence of nephrotoxicity is increasing because the duration of tacrolimus administration has increased. ${ }^{24}$ Four of our patients (6\%) experienced renal impairment, and tacrolimus was discontinued in 2 of these patients; both improved after discontinuing 
short-term tacrolimus.

One limitation of our study is its retrospective design. Additionally, patients' backgrounds in both the acute severe ulcerative group and in many steroid-dependent patients, initial tacrolimus dose, dose adjustment differences among institutions, and variations in trough levels appear to have influenced the short-term effects following tacrolimus therapy. In addition, several different drugs were being coadministered at the beginning of tacrolimus administration, which is a confounding factor. Regarding the long-term event-free survival rate, several treatment interventions were performed during relapse; therefore, we could not evaluate these rates accurately.

This retrospective study demonstrated that tacrolimus may be useful to induce short-term treatment response and may delay the need for colectomy in pediatric patients with steroid-dependent and steroid-refractory UC. No serious adverse events were seen in this study; tacrolimus was safely administered short-term, in our patients.

Despite the high rate of remission induction, only $14 \%$ of our patients maintained remission, and approximately $30 \%$ eventually required colectomy during long-term follow-up. Even if tacrolimus is effective, careful follow-up observation is necessary given the possible need for surgery. It is possible that bridging to AZA alone may not maintain long-term remission. Future studies are needed to determine how to maintain the effects of tacrolimus long-term.

\section{FINANCIAL SUPPORT}

This work was supported in part by Health and Labor Sciences Research Grants for research on intractable disease from the Ministry of Health, Labour, and Welfare of Japan.

\section{CONFLICT OF INTEREST}

No potential conflict of interest relevant to this article was reported.

\section{AUTHOR CONTRIBUTION}

Conceptualization: Yanagi T, Ushijima K. Methodology: Yanagi T, Tomomasa T, Tajiri H, Kunisaki R, Isihige T, Yamada H, Arai K, Yoden A, Aomatsu T, Nagata S, Uchida K, Ohtsuka Y, Shimizu T. Formal analysis: Yanagi T, Koga H. Writing - original draft: Yanagi T. Writing - review and editing: Yanagi T. Approval of final manuscript: all authors.

\section{ORCID}

$\begin{array}{ll}\text { Yanagi T } & \text { https://orcid.org/0000-0003-2453-8238 } \\ \text { Ushijima K } & \text { https://orcid.org/0000-0002-4349-1781 } \\ \text { Koga H } & \text { https://orcid.org/0000-0001-6266-3393 } \\ \text { Tomomasa T } & \text { https://orcid.org/0000-0002-3494-8719 } \\ \text { Tajiri H } & \text { https://orcid.org/0000-0002-8100-2715 } \\ \text { Kunisaki R } & \text { https://orcid.org/0000-0003-3083-9600 } \\ \text { Isihige T } & \text { https://orcid.org/0000-0002-2409-7359 } \\ \text { Yamada H } & \text { https://orcid.org/0000-0002-1167-2297 } \\ \text { Arai K } & \text { https://orcid.org/0000-0002-6440-4640 } \\ \text { Yoden A } & \text { https://orcid.org/0000-0001-5144-3707 } \\ \text { Aomatsu T } & \text { https://orcid.org/0000-0001-8890-5573 } \\ \text { Nagata S } & \text { https://orcid.org/0000-0002-2319-0885 } \\ \text { Uchida K } & \text { https://orcid.org/0000-0003-2272-3755 } \\ \text { Ohtsuka Y } & \text { https://orcid.org/0000-0002-8109-084X } \\ \text { Shimizu T } & \text { https://orcid.org/0000-0003-0364-0022 }\end{array}$

\section{ACKNOWLEDGEMENTS}

The authors thank the participating members of the Ministry of Health, Labour and Welfare of Japan's Inflammatory Bowel Diseases Study Group, especially the Department of Gastroenterology and Hepatology, Tokyo Medical and Dental University (Mamoru Watanabe); Department of Internal Medicine, Sakura Medical Center, Toho University (Yasuo Suzuki); Department of Internal Medicine, National Defense Medical College (Soichiro Miura and Ryota Hokari); and the Center for Advanced IBD Research and Treatment, Kitasato Institute Hospital, Kitasato University (Toshifumi Hibi) for their contributions to this work.

\section{REFERENCES}

1. Van Limbergen J, Russell RK, Drummond HE, et al. Definition of phenotypic characteristics of childhood-onset inflammatory bowel disease. Gastroenterology 2008;135:1114-1122.

2. Ishige $\mathrm{T}$, Tomomasa $\mathrm{T}$, Takebayashi $\mathrm{T}$, et al. Inflammatory bowel disease in children: epidemiological analysis of the nationwide IBD registry in Japan. J Gastroenterol 2010;45:91 1-917.

3. Turner D, Levine A, Escher JC, et al. Management of pediatric ulcerative colitis: joint ECCO and ESPGHAN evidence-based consensus guidelines. J Pediatr Gastroenterol Nutr 2012;55: 340-361.

4. Turner D, Ruemmele FM, Orlanski-Meyer E, et al. Management of paediatric ulcerative colitis, part 2: acute severe coli- 
tis-an evidence-based consensus guideline from the European Crohn's and Colitis Organization and the European Society of Paediatric Gastroenterology, Hepatology and Nutrition. J Pediatr Gastroenterol Nutr 2018;67:292-310.

5. Navas-López VM, Blasco Alonso J, Serrano Nieto MJ, Girón Fernández-Crehuet F, Argos Rodriguez MD, Sierra Salinas C. Oral tacrolimus for pediatric steroid-resistant ulcerative colitis. J Crohns Colitis 2014;8:64-69.

6. Turner D, Griffiths AM. Acute severe ulcerative colitis in children: a systematic review. Inflamm Bowel Dis 2011;17:440449.

7. Kino T, Hatanaka H, Miyata S, et al. FK-506, a novel immunosuppressant isolated from a Streptomyces. II. Immunosuppressive effect of FK-506 in vitro. J Antibiot (Tokyo) 1987;40: 1256-1265.

8. Kelly PA, Burckart GJ, Venkataramanan R. Tacrolimus: a new immunosuppressive agent. Am J Health Syst Pharm 1995;52: 1521-1535.

9. Kino T, Hatanaka H, Hashimoto M, et al. FK-506, a novel immunosuppressant isolated from a Streptomyces. I. Fermentation, isolation, and physico-chemical and biological characteristics. J Antibiot (Tokyo) 1987;40:1249-1255.

10. Ogata H, Matsui T, Nakamura M, et al. A randomised dose finding study of oral tacrolimus (FK506) therapy in refractory ulcerative colitis. Gut 2006;55:1255-1262.

11. Komaki Y, Komaki F, Ido A, Sakuraba A. Efficacy and safety of tacrolimus therapy for active ulcerative colitis; a systematic review and meta-analysis. J Crohns Colitis 2016;10:484-494.

12. Matsuoka K, Hibi T. Treatment guidelines in inflammatory bowel disease: the Japanese perspectives. Dig Dis 2013;31: 363-367.

13. IBD Working Group of the European Society for Paediatric Gastroenterology, Hepatology and Nutrition. Inflammatory bowel disease in children and adolescents: recommendations for diagnosis-the Porto criteria. J Pediatr Gastroenterol Nutr 2005;41:1-7.

14. Marion JF, Rubin PH, Present DH. Differential diagnosis of chronic ulcerative colitis and Crohn's disease. In: Kirsner JB, ed. Inflammatory bowel disease. 5th ed. Philadelphia: WB Saunders, 2000:315-325.

15. Turner D, Otley AR, Mack D, et al. Development, validation, and evaluation of a Pediatric Ulcerative Colitis Activity Index: a prospective multicenter study. Gastroenterology 2007;133: $423-432$.

16. Romano C, Syed S, Valenti S, Kugathasan S. Management of acute severe colitis in children with ulcerative colitis in the biologics era. Pediatrics 2016;137: e20151184.

17. Turner D, Walsh CM, Benchimol EI, et al. Severe paediatric ulcerative colitis: incidence, outcomes and optimal timing for second-line therapy. Gut 2008;57:331-338.

18. Turner D, Mack D, Leleiko N, et al. Severe pediatric ulcerative colitis: a prospective multicenter study of outcomes and predictors of response. Gastroenterology 2010;138:2282-2291.

19. Bousvaros A, Wang A, Leichtner AM. Tacrolimus (FK-506) treatment of fulminant colitis in a child. J Pediatr Gastroenterol Nutr 1996;23:329-333.

20. Bousvaros A, Kirschner BS, Werlin SL, et al. Oral tacrolimus treatment of severe colitis in children. J Pediatr 2000;137:794799.

21. Ziring DA, Wu SS, Mow WS, Martín MG, Mehra M, Ament ME. Oral tacrolimus for steroid-dependent and steroid-resistant ulcerative colitis in children. J Pediatr Gastroenterol Nutr 2007;45:306-311.

22. Watson S, Pensabene L, Mitchell P, Bousvaros A. Outcomes and adverse events in children and young adults undergoing tacrolimus therapy for steroid-refractory colitis. Inflamm Bowel Dis 2011;17:22-29.

23. Hamel B, Wu M, Hamel EO, Bass DM, Park KT. Outcome of tacrolimus and vedolizumab after corticosteroid and antiTNF failure in paediatric severe colitis. BMJ Open Gastroenterol 2018;5:e000195.

24. Hosoi K, Arai K, Matsuoka K, et al. Prolonged tacrolimus for pediatric gastrointestinal disorder: double-edged sword? Pediatr Int 2017;59:588-592 
See "Tacrolimus for ulcerative colitis in children: a multicenter survey in Japan" on page 476-485.

Supplementary Material 1. Supplement tacrolimus treatment questionnaire for pediatric UC.

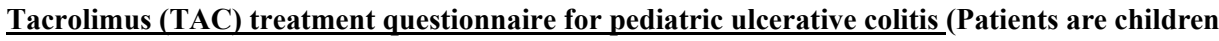

under 17 years of age receiving their first dose of tacrolimus)

Sex: (Male/Female) Birth date:

year month day

Height and weight at diagnosis: BW $\mathrm{kg} ; \mathrm{Ht}$ $\mathrm{cm}$

Family history: (Yes No)

History of disease other than ulcerative colitis: (Yes

No)

- At diagnosis of ulcerative colitis:

- Severity: mild, moderate, severe $\quad$ (PUCAI:

- Disease extent: Proctitis, Left-sided colitis, Pancolitis Matt's grade

(1) Treatment history before TAC administration: (circle as appropriate):

5ASA/SASP, Steroid, AZA/6-MP, Leukocyte apheresis, Cyclosporine, Infliximab Other (specify:

(2) Reason for TAC administration (circle as appropriate):

Steroid-dependent, Steroid-refractory, Other (specify:

(3) Characteristics at the beginning of TAC administration (circle as appropriate or provide data):

- Outpatient Hospitalized

- Age at the start of TAC administration years months

- Start date of administration: year month day

- Severity: mild, moderate, severe PUCAI:

- Disease extent: Proctitis, Left-sided colitis, Pancolitis Matt's grade:

- Total steroid dose before TAC administration:

$1.0 \mathrm{~g} \quad 2.0-5 \mathrm{~g} \quad 3.5-10 \mathrm{~g} \quad 4.10-20 \mathrm{~g} \quad>5.20 \mathrm{~g}$

-Initial tacrolimus dose: $\mathrm{mg} /$ day $\mathrm{mg} / \mathrm{kg} / \mathrm{day})$

(4) Blood concentration profile after TAC administration

$\rightarrow$ Please complete the table on the next page and provide all measurements for data within 3 weeks of TAC administration.

\section{(5) Short-term (2 weeks) effect}

Response to TAC is defined as a PUCAI score decrease of $\geq 20$ points compared with baseline

Remission: PUCAI $<10$

Effect: Yes / No If "Yes" $\rightarrow$ Remission / Response (circle appropriate choice) 
(6-1) If you circled "Yes" (Remission or Response) in Question 5:

(1) Last day of TAC administration: year month day (administration period weeks)

Reason for discontinuation: Remission / Insurance restrictions (3 months) / Relapse weeks) / Side effect ( ) / Operation / Other (specify:

(2) Additional treatment during TAC administration (for maintenance therapy):

AZA/6MP: Yes / No; Other (specify:

(6-2) If you circled "No" for "Effect" in Question 5:

(1) Last day of TAC administration: year month day

(2) New treatment after discontinuing TAC:

Steroid, AZA/6-MP, Leukocyte apheresis, Cyclosporine, Infliximab, Operation year month day), Other (specify:

\section{(7) Long-term (1 year) effects}

(1) Progress from the first dose of TAC to 1 year:

Relapse No / Yes ("Yes" $\rightarrow$ weeks form first TAC dose)

(2) Patient's condition 1 year after initial TAC administration:

Maintaining remission / Treating for relapse

PUCAI 1-year after initial TAC dose:

If surgery was performed: year month day

(8) Adverse effects secondary to TAC administration: Yes / No

Hypomagnesaemia / tremor / headache / hypertension / hyperglycemia / infection / renal disorder / other (specify:

)

(9) Treatment course

\begin{tabular}{|c|c|c|c|c|c|c|}
\hline & $\begin{array}{l}\text { At the start of } \\
\text { administration }\end{array}$ & $\left(\begin{array}{cc}2 \text { Weeks } \\
\mathrm{m}\end{array}\right.$ & $\begin{array}{l}4 \text { Weeks } \\
\left(\begin{array}{cc}\mathrm{m} & \mathrm{d}\end{array}\right)\end{array}$ & $\begin{array}{c}8 \text { Weeks } \\
\left(\begin{array}{ccc}\mathrm{m} & \mathrm{d}\end{array}\right)\end{array}$ & $\begin{array}{c}\text { At TAC } \\
\text { discontinuation } \\
\left.\begin{array}{rl}\mathrm{m} & \mathrm{d}\end{array}\right)\end{array}$ & $\begin{array}{l}1 \text { year after } \\
\text { TAC } \\
\left(\begin{array}{ll}\text { m } & \text { d }\end{array}\right)\end{array}$ \\
\hline 1. Tacrolimus (TAC) dose & $\mathrm{mg} /$ day & $\mathrm{mg} / \mathrm{day}$ & $\mathrm{mg} / \mathrm{day}$ & $\mathrm{mg} /$ day & $\mathrm{mg} /$ day & $\mathrm{mg} /$ day \\
\hline 2. $5 \mathrm{ASA} / \mathrm{SASP}$ dose & $\mathrm{mg} /$ day & $\mathrm{mg} / \mathrm{day}$ & $\mathrm{mg} / \mathrm{day}$ & $\mathrm{mg} /$ day & $\mathrm{mg} /$ day & $\mathrm{mg} /$ day \\
\hline 3. Steroid dose & $\mathrm{mg} /$ day & $\mathrm{mg} / \mathrm{day}$ & $\mathrm{mg} / \mathrm{day}$ & $\mathrm{mg} /$ day & $\mathrm{mg} /$ day & $\mathrm{mg} /$ day \\
\hline 4. AZA/6-MP dose & $\mathrm{mg} / \mathrm{day}$ & $\mathrm{mg} / \mathrm{day}$ & $\mathrm{mg} / \mathrm{day}$ & $\mathrm{mg} / \mathrm{day}$ & $\mathrm{mg} /$ day & $\mathrm{mg} / \mathrm{day}$ \\
\hline 5. Leukocyte apheresis & $\mathrm{Y} / \mathrm{N}$ & $\mathrm{Y} / \mathrm{N}$ & $\mathrm{Y} / \mathrm{N}$ & $\mathrm{Y} / \mathrm{N}$ & $\mathrm{Y} / \mathrm{N}$ & $\mathrm{Y} / \mathrm{N}$ \\
\hline $\begin{array}{l}\text { 6.Other treatment(s) } \\
(\end{array}$ & & & & & & \\
\hline( & & & & & & \\
\hline Height & $\mathrm{cm}$ & $\mathrm{cm}$ & $\mathrm{cm}$ & $\mathrm{cm}$ & $\mathrm{cm}$ & $\mathrm{cm}$ \\
\hline Body Weight & $\mathrm{kg}$ & $\mathrm{kg}$ & $\mathrm{kg}$ & $\mathrm{kg}$ & $\mathrm{kg}$ & $\mathrm{kg}$ \\
\hline PUCAI & & & & & & \\
\hline
\end{tabular}


Tacrolimus blood concentration over time

\begin{tabular}{|c|c|c|c|c|}
\hline $\begin{array}{l}\text { Administration } \\
\text { course }\end{array}$ & $\begin{array}{l}\text { Blood trough } \\
\text { concentration } \\
(\mathrm{nmol} / \mathrm{L})\end{array}$ & $\begin{array}{c}\text { Dose } \\
\text { after } \\
\text { changing } \\
\text { to TAC } \\
\text { (mg/day) }\end{array}$ & PUCAI & \\
\hline After 12 hours & & $\rightarrow$ & $\mathrm{X}$ & \\
\hline After 24 hours & & $\rightarrow$ & $\mathrm{X}$ & \multirow[t]{6}{*}{$\begin{array}{l}\text { Please add any additional comments or } \\
\text { impressions. }\end{array}$} \\
\hline Day ( 2 ) & & $\rightarrow$ & & \\
\hline Day ( ) & & $\rightarrow$ & & \\
\hline Day ( ) & & $\rightarrow$ & & \\
\hline Day ( ) & & $\rightarrow$ & & \\
\hline Day ( ) & & $\rightarrow$ & & \\
\hline Day ( ) & & $\rightarrow$ & & \\
\hline 4 weeks & & $\rightarrow$ & & \\
\hline 3 months & & $\rightarrow$ & & \\
\hline ( ) months & & $\rightarrow$ & & $\begin{array}{l}\text { If }>3 \text { months, please provide } \\
\text { the number of months after } \\
\text { first TAC administration. }\end{array}$ \\
\hline ( ) months & & $\rightarrow$ & & $\begin{array}{ccc}\text { Last } & \text { measurement date } \\
\mathrm{m} & \mathrm{d}\end{array}$ \\
\hline
\end{tabular}

